involved in all of NIH's early gene trials, RAC represents "a redundancy built into the system which I believe is no longer necessary."

Philip Noguchi, head of FDA's Division of Cellular and Gene Therapies, says RAC does serve a useful function, but notes that "There are certain things that the FDA does better and there are certain things that the RAC does better." What RAC does well, Noguchi says, is discuss broad concepts in public, "the very real issues [are] Is it time? Is it not time? I'm scared of this. I'm not scared of this. ... FDA can use those concepts in applying them to specific cases." RAC comes unstuck and inconsistencies begin to creep in when RAC is reviewing individual protocols, Noguchi says. "Their job is not to try to really understand the dangers or anticipate them. That's our job." Anderson agrees, and says that RAC is wasting its time reviewing many of the protocols it sees, although he remains a strong supporter of RAC's role in the review of distinctly new technologies, particularly any "innovative approach that has not been used before, and therefore is a potential public risk." Anderson says such review should go beyond discussion only of issues like germline and in utero gene therapy.

The Motulsky-Orkin panel will conduct a sweeping review of NIH's role in gene therapy research. An analysis of the question of whether NIH support should be concentrated at so-called centres of excellence reflects Varmus' concern that some human gene therapy trials are scientifically weak. "There is very little evidence of therapeutic success" in gene therapy, Varmus says, suggesting that NIH's investment may be insufficient in more basic studies such as stem cell biology.

The panel's review of NIH funding as a whole will include data gathering on what's happening among burgeoning gene therapy companies. Conflict of interest is also on the Motulsky-Orkin panel's agenda.

Members of Verma's panel plan to submit a report to Varmus after several more meetings. Coupled with the results of Motulsky and Orkin's panel, which met for the first time on 15 May, the report should provide Varmus with a more comprehensive picture of NIH's involvement in gene therapy.

"There will be a time, I don't know if it's one year from now, or 10 years from now, or 50 years from now, when we won't use RAC, because gene therapy is going to be common practice," Varmus told Verma's panel at its May meeting. "We're moving away as we always have from strict oversight to no oversight. The issue is: "How big is the next step?"

MrChaEl KLeIN Baltimore

\title{
New oversight for peer review
}

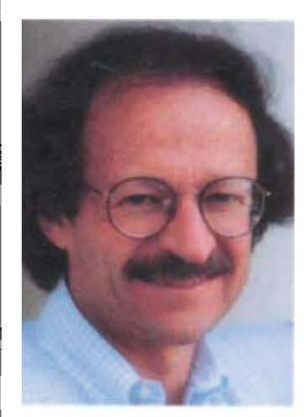

Varmus: accepts review of peer review.
The US National Institutes of Health (NIH) is to set up a new oversight body responsible for policy recommendations about the NIH peer-review system. Through peer review the Institutes distribute more than $\$ 8$ billion of government money to scientists each year.

The new oversight body stems from a recommendation made last month by a working group that Harold Varmus, Director of the NIH, appointed to examine the structure and activities of NIH's Division of Research Grants (DRG), which conducts the initial scientific review of about 80 per cent of the applications that land on NIH's doorstep.

Marvin Cassman, Acting Director of NIH's National Institute of General Medical Sciences, headed the working group, comprising senior scientists from both $\mathrm{NIH}$ and the extramural community. In closed-door meetings, they interviewed 27 senior colleagues about peer review at NIH.
Several concerns emerged. These included the belief that the relationship between the DRG and the institutes can be confrontational rather than collaborative; that peerreview bodies within both the DRG and the institutes do not apply similar standards or procedures; that the criteria for deciding where a grant will be reviewed seems arbitrary; and that the review bodies or 'study sections' within the DRG, are not responsive enough to changes in science. The working group recommended that the new oversight committee address these concerns.

In a separate recommendation, Cassman's group said that both the DRG and the institutes should continue to carry out initial reviews, but that the new oversight body should decide, probably through guidelines, what is reviewed where.

The working group concluded also that the DRG should remain, as it has been since its creation in 1946, a central body that reviews the bulk of grant applications independently of the institutes. The alternative would be to disseminate all initial scientific reviews to each of the institutes. Like others before them, Cassman's group acknowledged that such a move could compromise the quality of the scientific research because the review might be subject to policy decisions about which areas of research should go ahead rather than being based on scientific merit.

There was less agreement among members of the working group about whether the DRG should remain autonomous, which in this case means with direct responsibility to the director of the NIH rather than reporting via the office responsible for extramural research.

Varmus, however, has decided to keep the division autonomous for now, in part to make the now-vacant post of DRG director attractive to potential candidates.

Many of the DRG staff crowded in to hear the working group's recommendations last month. They had been hearing rumours for some time about the contents of the wellguarded report. Their reviews on the day were mixed, ranging from relief that the division would remain autonomous, to curiosity as to whether the new oversight body would be any more than another layer of bureaucracy.

HELEN GAVAGHAN 